\title{
RANKING THE OPTIMUM TARIFF AND THE MAXIMUM REVENUE TARIFF
}

\author{
Edward TOWER* \\ Duke University, Durham, $\mathrm{NC} 2770 \circ$, U.S.A.
}

Received April 1975, revised version received October 1976

\section{Introduction}

This note uses a two-commodity model to demonstrate that if (1) the tariff revenue is given to the private sector, (2) the home trade indifference curves are strictly concave and (3) the foreign offer curve has a continuous first derivative, then the maximum revenue tariff will exceed the optimum tariff. ${ }^{1}$

\section{Can the maximum revenue and optimum tariffs be the same?}

Throughout the analysis, we assume that the home country produces and consumes two goods. Fig. 1 shows the quantity of home exports on the vertical axis with the quantity of home imports on the horizontal. $F$ denotes the foreign offer curve, and $I^{*}$ is the home trade indifference curve which is tangent to it at $Q^{*}$, so that $Q^{*}$ is the equilibrium trading point generated by the optimum home tariff. To determine the tariff which maximizes revenue measured in units of the exportable when the tariff revenue is given to the private sector, we hold tariff revenue constant at $O X$ while pivoting the internal price line about $X$, where the siope of this line is denoted by $p$ and shows the relative price of the import faced by the private sector, i.e. the internal relative price of the import. Its points of tangency with home trade indifference curves trace out a revenue-constrained home offer curve (denoted by $H R C$ ). If this offer curve never intersects the foreign one, the world is in a staie of chronic excess demand at any price ratio, and search must proceed for an equilibrium in which tariff revenues are smaller. Similarly, if there are muitiple intersections, we would construct an offer curve corresponding to more tariff revenue than before. Once the offer curve which is

\footnotetext{
*The author is also affiliated with the U.S. Treasury. J.N. Bhagwati, H.G. Johnson and the referee helped impiove earlier drafts.

${ }^{1} \mathrm{~A}$ geometric discussion of the maximum revenue tariff is provided in Tower (1976), which in combination with Johnson (1951) can be used as an introduction to this paper.
} 
tangent to the foreign offer curve is found, the maximum revenue tariff is calculated according to

$$
p=(1+t) \pi
$$

where $p$ and $\pi$ are the internal and external relative prices of the import at the tangency point (given by the slopes of the lines from the tangency point to $X$ and $O$ respectively) and $t$ is the tariff rate. If it is desired to maximize tariff revenue measured in units of the import and evaluated at the internal price ratio, the same procedure is used except that the offer curves are drawn by pivoting the internal price line through $M$. In both cases, the maximum revenue tariff is found at the point of tangency of the foreign offer curve with the appropriately defined domestic one.

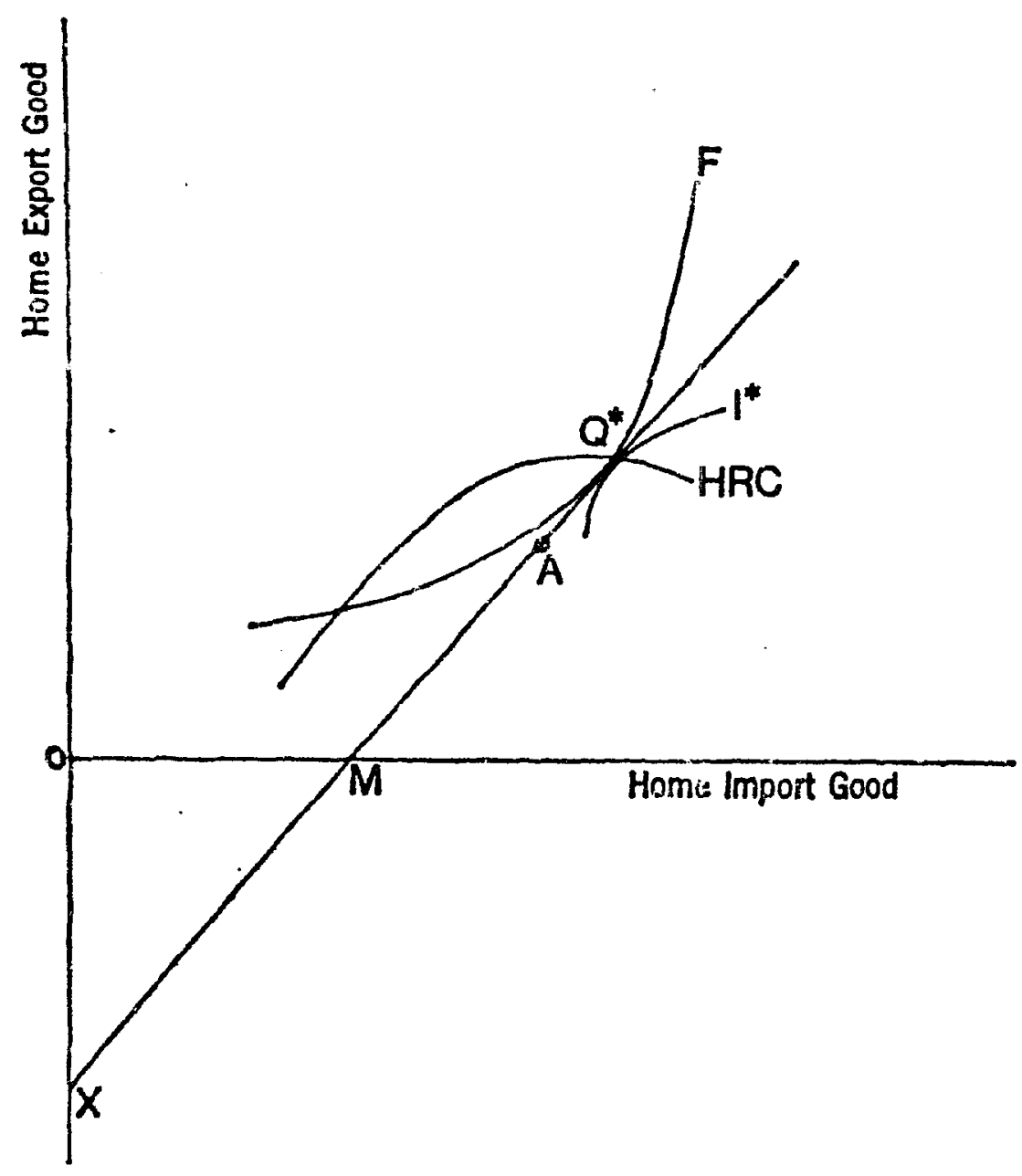

Fig. 1

The optimimo home tariff can also generate maximum revenue only if the revenue-constrained offer curve tirough $Q^{*}$ is tangent to the foreign offer curve at that point. However, this is possible only if it coincides with the price line $X Q^{*}$ in some range close to $Q^{*}$ between $X$ and $Q^{*}-$ i.e. if and only if it passes through some point $A$, where $A$ lies along $X Q^{*}$; and to pass through $A$, it must be tangent to an indifference curve at $A$. But if the home trade indifference 
curves are strictly concave, this means that the two indifference curves which are tangent to $X Q^{*}$ at $A$ and $Q^{*}$ must intersect, which is ruled out by assumption. Thus, if the foreign offer curve is smooth and home trade indifference curves are strictly concave, the maximum revenue tariff must differ from the optimum tariff. $^{2}$

\section{Is the maximum revenue tariff always larger than the optimum tariff?}

Now, we show that the maximum revenue tariff will exceed the optimum one. Fig. 2 shows two trade indifference curves for the home country superimposed on the foreign offer curve. We assume the trade indifference curves are strictly concave and the foreign offer curve is smooth. To make our proof general, we have purposely chosen a rather badly behaved foreign offer curve which intersects some terms of trade lines emanating from the origin more than once, for as Kemp (1968, pp. 153-4) (among others) has noted, such a configuration is possible if the foreign exportable is inferior in foreign consumption and the foreign country restricts trade with a tariff.

Curve $I_{1}$ is a representative trade indifference curve which intersects the foreign offer curve more than once. Now suppose a tarifi is imposed which causes the two offer curves to intersect at $Q_{L}$, where $Q_{L}$ lies further along the foreign offer curve from the origin than $Q^{*}$. Since the slope of $I_{1}$ at $Q_{L}$ is the relative internal price of the import, it is clear that $X_{L}$ and $M_{L}$ are the tariff revenues expressed in units of the exportable and importable respectively (where $X_{L} Q_{L}$ is the tangent to $I_{1}$ at $Q_{L}$ ) and vertical deviations from the origin in either direction represent positive quantities. Now consider the equilibrium at $\mathcal{Q}_{H}$ generated by the tariff which causes the offer curves to intersect at $Q_{H}$, where $Q_{H}$ is any intersection of $I_{1}$ with the foreign offer curve which lies between the origin and $Q^{*}$. The same technique is used to obtain $X_{H}$ and $M_{H}$ as was used to find $X_{Z}$ and $M_{L}$. From the strict concavity of $I_{1}$, the internal price line at $Q_{H}$ is steeper than at $Q_{L}$. This, combined with the fact that $Q_{H}$ lies below $X_{L} Q_{L}$, implies that $M_{F}$ lies to the right of $M_{L}$ and $X_{H}$ lies below $X_{L}$. This means that the tariff revenue corresponding to $Q_{H}$ exceeds the tariff revenue corresponding to $Q_{L}$ for both of the corresponding measures. Thus we have shown that the equili-

\footnotetext{
${ }^{2}$ However, it is easy to sce that if the foreign offer curve has a kink at $Q^{*}$, the revenueconstrained offer curve through $Q^{*}$ could touch the foreign offer only once without having to be tangent to the price line through that same point. Similarly, if in some range the two goods are perfect substitutes in home consumption or production, the home trade indifference curves will have flat segments. If the one which is tangent to the foreign offer at $Q^{*}$ has a flat segment in that neighborhood, a revenue-constrained offer curve would coincide with $X Q^{*}$ on either side of $Q^{*}$. In both cases, optimum and maximum revenue tariffs may be the same. Finally, a ranking is impossible unless we assume that the home free trade offer curve intersects the foreign one somewhere besides the origin. Otherwise, real income and revenue are both maximized at all positive tariffs.
} 
brium which generates maximum tariff revenue must lie along the foreign offer curve between the origin and $Q^{*}$, and from the previous section we know it cannot lie at $Q^{*}$.

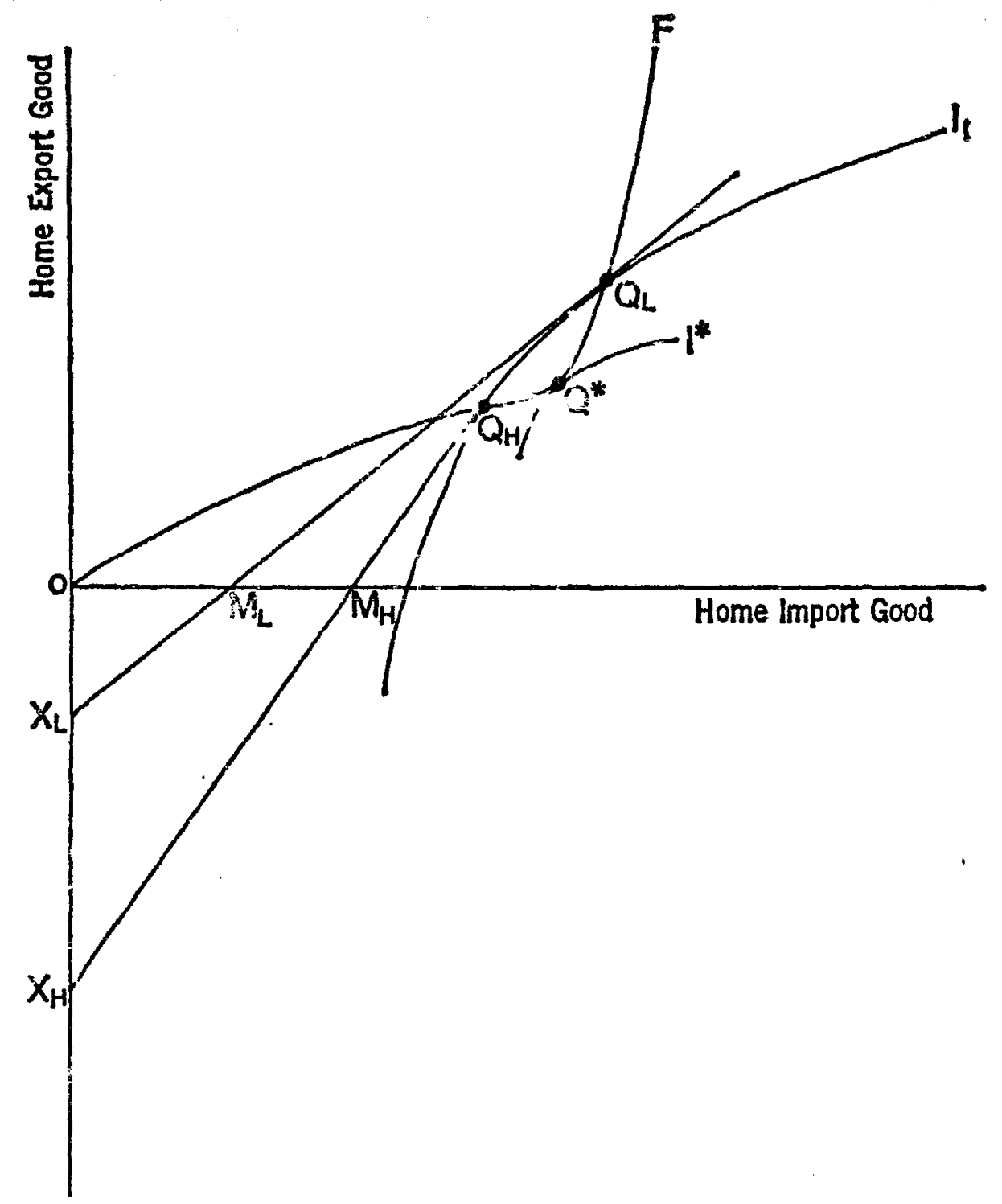

Fig. 2

Fig. 3 shows a tariff-distorted home offer curve denoted by $O H$. If the home offer curve were to intersect the foreign offer curve at $Q$, then corresponding to that equilibrium, would be an external relative price of the import, $\pi$, equal to the slope of $O Q$, and an internal relative price, $p$, given by the slope of $X Q$ (where $X Q$ is tangent to the home trade indifference curve at $Q$ ). Thus revenue measured in units of the exportable is given by $X$. Rewriting eq. (1), and substituting for $p$ and $\pi$ from fig. 3 , yields

$$
t=(p-\pi)_{i} \pi=O_{X_{i}^{\prime}} Q T,
$$

where $t$ is the tariff rate corresponding to the given home offer curve. This can be rewritten as

$$
O X=t \cdot Q T
$$


Since $O X M$ and $T Q M$ are similar triangles, and since corresponding sides of such triangles must be proportional, it follows that

$$
O M /(O T-O M)=O X / Q T \text {. }
$$

Sclving (4) for $O M$ and substituting from (3) yields

$$
O M=(O T) /[1+(1 / t)] .
$$

Equation (5) states that the tariff revenue measured in units of the importable will be an increasing function of both the horizontal coordinate of the equilibrium point and the tariff rate. Moreover, from (3) it is clear that tariff revenue measured in units of the exportable will be an increasing function of both the vertical coordinate and the tariff rate.

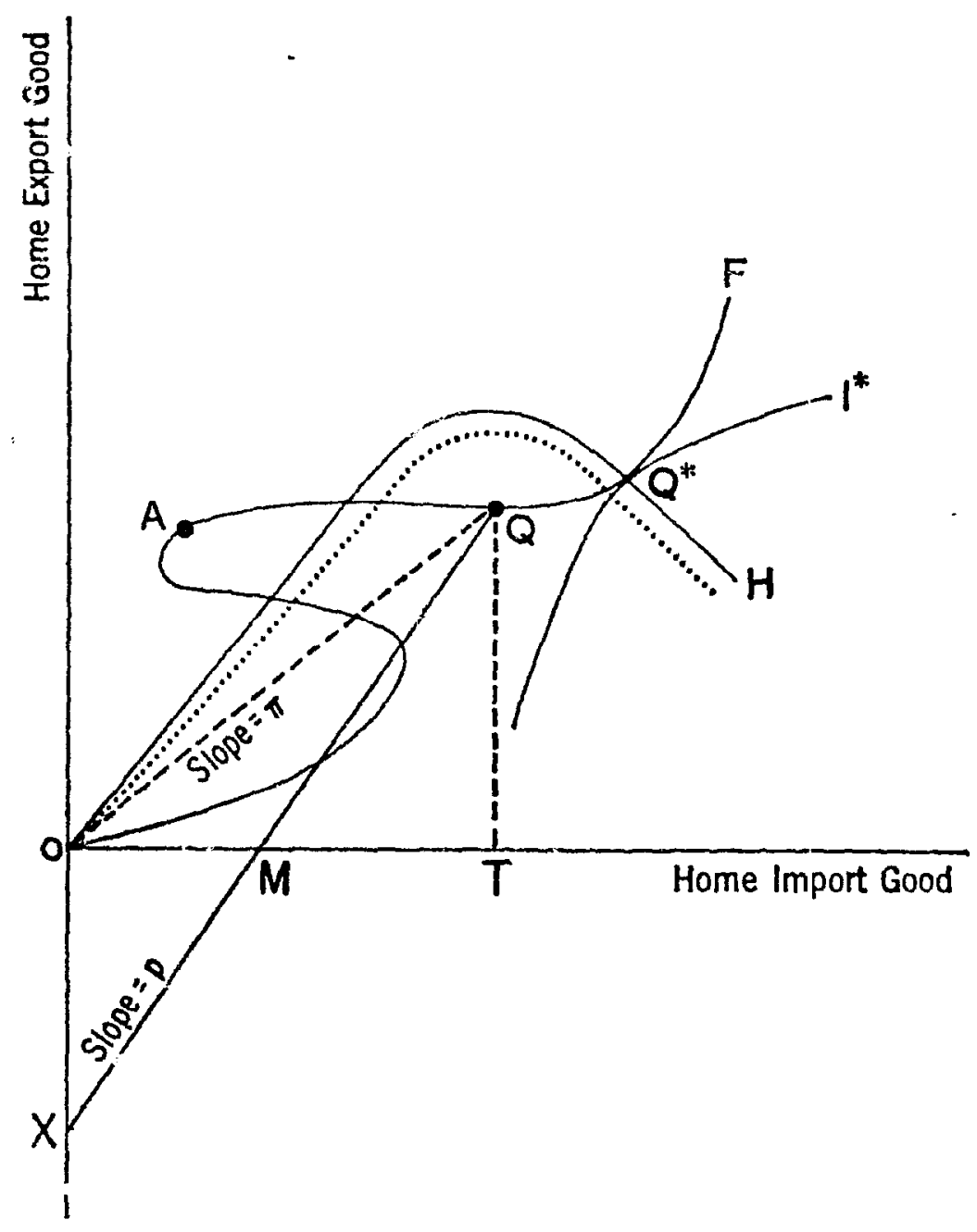

Fig. 3

The same figure illustrates the relationship between a foreign offer curve and the home offer curve which is distorted by the optimum home tariff. As Johnson $(1958$, p. 34$)$ notes, 'The reciprocal demand curve traced out by a higher tariff rate will always lie inside the curve traced out by a lower tariff rate.' 
Thus, as the tariff is increased, the home offer chrve will shift downward and be replaced by curves like the dotted one. This means that equilibrium points like $A$ which lie on the foreign offer curve between $Q^{*}$ and $O$, and outside the home offer curve passing through $Q^{*}$, are attainable only when the home tariff is less than the optimum level. Thus, if the maximum revenue tariff caused the home ofier to pass through $A$, the maximum revenue tariff would be less than the optimum tariff. But this is impossible, because point $Q^{*}$ is attainable with a higher tariff than is $A$, and both the vertical and horizontal coordinates of $Q^{*}$ exceed those of $A .^{3}$ Thus, the tariff revenue corresponding to the equilibrium at $Q^{*}$ is necessarily, greater than that at $A$ no matter how the revenue is measured. Since the equilibrium with maximum revenue must occur along the foreign offer in the range between $O$ and $Q^{*}$, it must occur inside the home offer passing through $Q^{*}$. Thus, we have proven our proposition.

\section{Comparison with other studies}

We have proven that the maximum revenue tariff is always greater than the optimum tariff if the foreign offer curve is not kinked, the home trade indifference curves are strictly concave and the two free trade offer curves intersect somewhere besides the origin. Bhagwati and Srinivasan (1974), Caves and Jones (1973) and Johnson (1951) ${ }^{4}$ also proved that the maximum revenue tariff generally exceeds the optimum tariff. Their proofs are considerably less powerful than ours, for they assume that the tariff revenue is measured in units of the exportable, while we have shown that the proposition holds regardless of wi iether

\footnotetext{
${ }^{3}$ For the equilibrium at $Q^{*}$ to define the optimum tariff, the foreign offer curve in the range between $O$ and $Q^{*}$ must lie to the left of the home trade indifference curve through $Q^{*}$, I $t$ is in the nature of offer curves that a country's welfare increases as the equilibrium mowes out from the origin along the offer curve. Since the foreign indifference curves have positive slopes, and foreign welfare would be reduced by any movement in a southeasterly direction, no part of the foreign offer curve in the range between $O$ and $Q^{*}$ can lie northwest of $Q^{*}$. Hence $Q^{*}$ must lie northeast of $A$.

${ }^{4} \mathrm{~J}$ ohnson (1951) first raised the questions considered here. His derivation of the formula for the maximum revenue tariff assumed that the government spent the revenue, while his proof that the maximum revenue tariff exceeds the optimum tariff assumed that the revenue was given to the private sector. It is not hard to show that his formula applies to both cases, but that the maximum revenue tariff when the government spends the revenue itself on either good may exceed or fall short of the optimum tariff when the revenue is given to the private sector, even when the foreign oft-r curve has the normal curvature, home production of both goods is fixed and the underlying home consumption indifference curves are homothetic. Thus, the tariff may either rise or fall when a government which uses tariff policy to maximize its own command oyer goods and services gives way to one which uses the tariff to maximize suciety's real income. However, if the government charges itself the sime tariff that the private: sector pays, and spends the tariff revenue according to a prefsrence function which is homothetic and identical to the private sector's, then the analysis is the same no matter who spends the tariff revenuey and our earlier conclusions abo it ranking are preserved.
} 
the revenue is measured in units of the importable or exportable. ${ }^{5}$ Their logic consists of demonstrating that at the optimum tariff, revenue increases with the tariff; if revenue is a single-peaked function of the tariff, the maximum revenue tariff must exceed the optimum tariff. While Johnson never explicitly noted that single peakedness is necessary for his proof to be valid, both BhaswatiSrinivasan and Caves-Jones did make this assumption explicit. ${ }^{6}$ But there seems to be little justification for the assumption of single peakedness, and our proof does not utilize it.

Finally, the geometry used by Caves-Jones and Johnson to demonstrate that at the optimum tariff, revenue increases with the tariff is not sufficiently rigorous to be convincing and the calculus they used to demonstrate this proposition relies on the implicit assumption that the importable is not inferior in home consumption (an assumption which Bhagwati-Srinivasan made explicit), while our proof holds even in the presence of inferiority or the Giffen paradox. ${ }^{7}$

\footnotetext{
${ }^{5}$ However, Bhagwati and Srinivasan have extended the ranking of the two tariffs to the presence of illegal trade as well.

${ }^{6}$ Revenue will not be a single-peaked function of the tarifl' if there are more than two intersections of the foreign offer curve and a home revenue-constrained offer curve. This can happen so long as either the foreign offer curve or the home revenue-constrained offer curve has points of inflection, and these curves can have inflection points even when inferior goods are excluded. Finally, if there are multiple intersections between the foreign offer curve and any home tariff-distorted offer curve, revenue is no longer a single-valued function of the tariff.

${ }^{7} J o h n s o n ' s$ calculus proof hinges on the assumption that $(\mathrm{d} p / \mathrm{d} X)(\mathrm{d} X / \mathrm{d} t) \equiv \mathrm{d} p / \mathrm{d} t \geqq 0$, and the Caves-Jones proof in the supplement to their ch. 13 also requires that $\mathrm{d} p / \mathrm{d} t>0$, where $p$ is the internal relative price of the import and $t$ is the tariff. But it follows from Metzler (1949) that if the import is inferior in home consumption, the inequality may be reversed, even when the foreign offer curve has the usual slope (as it does at the optimum tariff point). Although Johnson did note that his ranking was not necessarily valid in the presence of the Giffen paradox, his method of proof may break down when the import is inferior in home consumption, even without being a Giffen good. Finally, none of the three treatments notes that the proof relies on the assumption that the foreign offer curve is smooth, and only Johnson explicitly mentions that perfect substitutability of imports for export goods must be ruled out.
}

\section{References}

Bhagwati, J.N. and T.N. Srinivasan, 1974, Smuggling and trade policy, in: J.N. Bhagwati, ed.s Jllegal transactions in international trade (North-Holland, Amsterdam) ch. 3.

Caves, R.E. and R.W. Jones, 1973, World trade and payments (Little, Brown, Boston).

Johnson, H.G., 1951, Optimum welfare and maximum revenue tariffs, Review of Economic Studies 19, 28-35.

Johnson, H.G., 1958, International trade and economic growth (Allen and Unwin, London).

Kemp, M.C., 1968, Some issues in the anaiysis of trade gains, Oxford Economic Papers 20, 149-161.

Metzler, L., 1949, Tariffs, international demand and domestic prices, Journal of Political Economy 57, 345-351.

Tower, E., 1976, The maximum revenue tariff, Malayan Economic Review 21. 